\title{
The Analysis of Total User Experience for B2C Mobile Shopping*
}

\author{
JIANG Sudong, CHEN Congcong, LI Xiao \\ School of computer and Information Science, Southwest University, Chongqing 400715, China \\ 15823007886@139.com,182023202227@139.com
}

\begin{abstract}
The B2C mobile shopping has become the highlight of the development of mobile e-commerce gradually, user experience is becoming increasingly important. Firstly, according to the "2012 of Chinese e-commerce market data monitoring report" published by the China Electronic Commerce Research Center, 10 typical B2C mobile shopping clients are selected as samples to analyze. Secondly, this paper analyzes the shopping process of samples, in order to establish the main components of total user experience for $\mathrm{B} 2 \mathrm{C}$ mobile shopping. The study contributes to the understanding of the whole process of the mobile shopping experience for e-commerce companies in objective way. Finally, this paper also gives some suggestions to improve the quality of user experience for mobile shopping.

Index Terms - Mobile B2C, Mobile Shopping, Total User Experience, Empirical Analysis
\end{abstract}

\section{I . Introduction}

Mobile Shopping has emerged form intuitive. The B2C (Business to Customer) mobile shopping is to purchase products or services through mobile terminals with wireless communication network in the $\mathrm{B} 2 \mathrm{C}$ businesses. According to China Electronic Commerce Research Center shows that in 2012 Chinese mobile shopping market transactions reached 55.04 billion, mobile shopping is e-commerce emerging growth highlights in the future [1]. More and more B2C ecommerce companies have launched mobile shopping client, the level of user experience reflects the quality of service is good or bad B2C e-commerce companies directly, the user experience is the key factor that affect the overall competitiveness of e-commerce businesses. A good user shopping experience is the goal of B2C e-commerce businesses and driving force of innovation.

The concept of "user experience" is to be widely known in the 1890s, it has been popularized by Donald Norman. According to the definition in ISO 9241-210, user experience is the user use the product, system or service perception impression and response [5]. User experience is operation process or use of a product or service, thinking, feeling, related to the products and services provided to the user's rational values and emotional experience [7]. Moeslinger thinks that includes practical experience, sensory experience and emotional experience as part of user experience. The total user experience is the whole processes that from user know the product, understand the product and give the feedback of product [8].

The total user experience for B2C mobile shopping is that the whole process of user to browsing goods, understanding goods and purchase with mobile shopping App. B2C mobile shopping user experience will impact on the user's purchase decision directly. Creating a good user experience for mobile shopping App will be provide a good shopping experience and increase the wishes of visiting to the mobile shopping App, so as to stimulate the user to make a purchasing decision. The B2C mobile shopping provide users with better service and experience help to enhance customer loyalty and increase of the customer groups, the user experience is more and more important in mobile e-commerce field. In this paper, we focus on the need for the total user experience for $\mathrm{B} 2 \mathrm{C}$ mobile shopping.

\section{II . The Total User Experience For B2C Mobile Shopping}

\section{A . Sample Selection}

According to the "2012 of Chinese e-commerce market data monitoring report" published by China Electronic Commerce Research Center. We know that the typical B2C ecommerce enterprises, which spread over $89.8 \%$ of 2012 China's B2C online shopping market 10 B2C e-commerce companies as: Tmall, Jingdong, Suning, TencentB2C, 51buy, VANCL,AmazonChina,Coo8,Dangdang,51buy, Newegg [1322]. These e-commerce companies have launched Mobile Shopping App in different operating system. These App will meet users' shopping needs that no limitations of time and space.

\section{B. The Introduction Of B2C Mobile Shopping Client}

The selected samples have different operating system versions. The introduction of B2C mobile shopping client as follows:

\footnotetext{
* Sudong Jiang is the 1st author(e-mail:15823007886@139.com). Xiao Li is the corresponding author (e-mail: 13883667520@139.com)
} 
Table I The Typical B2C Mobile Shopping Apps’ Introduction

\begin{tabular}{|l|l|l|l|}
\hline App Name & Business Type & User Type & Supported Operating System \\
\hline Jingdong & 3C Products & General Users & Android, iOS,Symbain, Windows, Phone, Windows 8 \\
\hline Suning & 3C Products & Purchasing Electronic Products Users & Android, iOS Windows Phone,Windows8 \\
\hline 51buy & 3C Products & Purchasing Electronic Products Users & Android, iOS \\
\hline Newegg & 3C Products & Purchasing Electronic Products Users & Android, iOS, Windows Phone,Windows 8 \\
\hline Coo8 & 3C Products & Purchasing Electronic Products Users & Android, iOS \\
\hline Tmall & General Merchandise & General Users & Android, iOS Windows Phone \\
\hline Tencent B2C & General Merchandise & General Users & Android, iOS \\
\hline AmazonChina & Books, Audio and Video Products & General Users & Android, iOS \\
\hline Dangdang & Books, Audio and Video Products & General Users & Android, iOS, Windows Phone \\
\hline VANCL & Clothing & Purchase Fashion Accessories Users & Android, iOS, Symbain, Windows Phone7 \\
\hline
\end{tabular}

\section{The Analysis Of B2C Mobile Client Shopping Process}

Consumer use the B2C mobile shopping App to complete a shopping transaction process. Kalakota\&Whinston think that the shopping process related to post purchase evaluation, purchase, purchase behavior in three stages[10].we have been given the generalized mobile $\mathrm{B} 2 \mathrm{C}$ shopping process as follows.

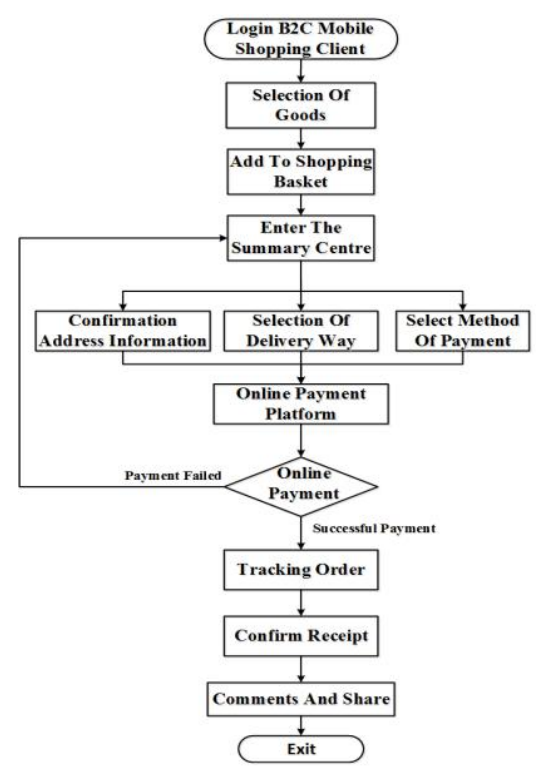

Fig. 1 The B2C Mobile Shopping Client Generalized Shopping Process

In the process of mobile shopping, there is a series of interactive behavior will occur between user and mobile shopping App. App's content and operation are the main factors, which impact to the users' shopping cognition. While mobile shopping is an emerging way to shop, but it is similar to the traditional shopping. Consumers have a cognitive process of goods that users select goods through different channels, such as search, category, promotional information, etc. Composition of final knowledge and attitude for goods, then they will make a shopping decision. If the consumer intends to buy the goods, they will add the goods to the shopping cart and confirm the address information, select payment method, online payment and other activities.

\section{The Main Components Of Total User Experience For B2C} Mobile Shopping

In this paper, we have established the main components of total user experience for B2C mobile shopping, which consists of Cognition-Decision, Checkout-Payment, LogisticsDistribution, Using-Feedback.

\section{1) Cognition-Decision}

Cognition-Decision is the first part of total user experience for $\mathrm{B} 2 \mathrm{C}$ mobile shopping. Consumers have a cognitive process of goods that users select goods through different channels, such as search, category, promotional information, recommendation, etc. They will compare a lot of goods and contact the merchant, as well as view the goods details and comments. These activities will be formed the final cognitive for goods, which determine whether add the good into shopping cart. Of course, the following three parts will also affect the user's purchasing decision. This part should focus on the departure from the user's cognitive needs and consider what factors will affect the generation of user's purchasing decision.

\section{2) Checkout-Payment}

This part is the summary on the purchase of goods and payment.Consumers will be confirmed the receptor's information, delivery way and method of payment. Payment and payment processes will affect the shopping experience.

\section{3) Logistics-Distribution}

This part of the business to arrange the shipment, distribution, picking and goods sent to consumers in the logistics node in accordance with the requirements of the users' order. Logistics -Distribution is an important part in the B2C mobile shopping total user experience. In particular, speed of delivery, delivery time, packaging, logistics service attitude have a direct impact on the user experience.

\section{4) Using-Feedback}

Using-Feedback is the last part of B2C mobile shopping total user experience. Consumers will confirm receipt and use of goods and the process of evaluation and sharing. They will give feedback the feeling of the good, logistics and other aspects of information through comment, also to share with friends through social tools. Social comment and sharing will increase the cognition of goods. 


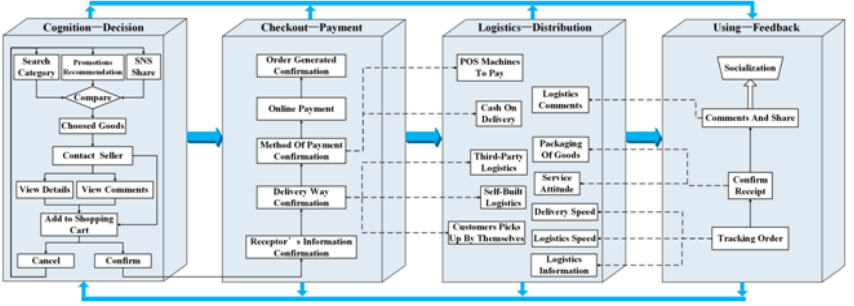

Fig. 2 The Main Components of Total User Experience for B2C Mobile Shopping

The user experience affects the users' purchasing decision directly. If consumers are displeasure at some part in B2C mobile shopping process, they also not satisfied with the services provided by the e-commerce businesses, these dissatisfied factors that may prevent the user reaches the next stage of shopping completely. These three parts of Cognition-
Decision, Checkout-Payment and Logistics-Distribution may be reflected in the part of Using-Feedback. Behind the three parts of Checkout-Payment, Logistics-Distribution, UsingFeedback will affect the part of Cognition-Decision. In addition, improvement of any part will contribute to total user experience for B2C mobile shopping. Therefore, we study all parts of total user experience for $\mathrm{B} 2 \mathrm{C}$ mobile shopping, in order to get the greatest satisfaction and a good shopping experience.

\section{III . The Comments Of 3C Product Mobile Shopping App}

Based on the result of the main components of total user experience, this paper comments the characteristics and inadequacies of the selected sample of $3 \mathrm{C}$ products' mobile shopping clients and gives some suggestions to improve the quality of user experience for mobile shopping.

Table II The Characteristics And Inadequacies Of 3C Product Mobile Shopping App And Suggestions

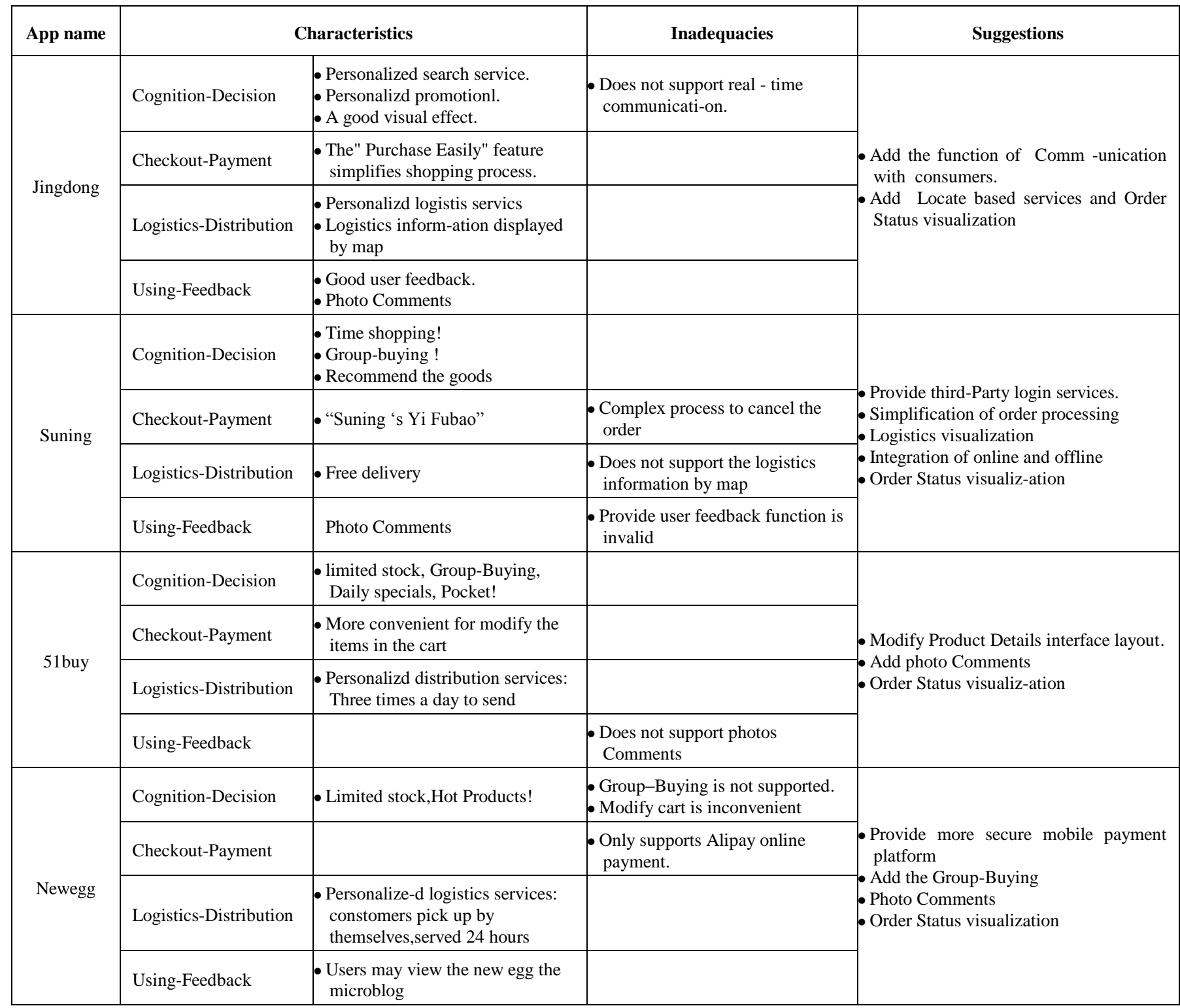




\section{IV . Conclusion And Future Directions}

The result of the main components of total user experience for B2C mobile shopping not only the understanding of the whole process of the mobile shopping experience for ecommerce companies in objective and comprehensive way, but also help to understand the attitude and willingness of users to make purchasing decisions' influencing factors. The aim of this paper is to provide methods improve user shopping experience. The total user experience for B2C Mobile shopping has a certain theoretical significance and practical value. If the $\mathrm{B} 2 \mathrm{C}$ mobile shopping client to give the user a good experience, not only to the successful completion of the user's goal, and should make the user feel friendly, but also the service system should be maximized to meet users' needs.

With the development of mobile e-commerce, mobile shopping could become an indispensable element in our lives, it is the main shopping way in the future. The user understands the B2C mobile shopping client in-depth, there will be generate more users' shopping needs. Mobile Shopping App should focus on users' needs and provide richer user experience. If some new technologies such as Location-based services (LBS), augmented reality (AR), Near Field Communication (NFC) and other technologies combine with mobile shopping, which will give user a new mobile shopping experience.

\section{References}

[1] China Electronic Commerce Research Center, http://b2b.toocle.com /detail--6075541.html,2012-12
[2] 2011 China B2C e-commerce market survey report , Hangzhou: China Electronic Commerce Research Center, 2011:

[3] 2012 China's e-commerce market data monitoring report . Hangzhou: China Electronic Commerce Research Center,2013-03:

[4] Effie LC. Law, VirpiRoto, Marc Hassenzahl. Understanding, Scoping and Defining User experience: A Survey Approach. Boston, MA, 2009.

[5] Lucas Danie.Understanding user experience.WebTechniques, 2000,5(8)

[6] Jakob Nielsen,Rolf Molich.E-COMMERCEUSER EXPERIENCE,2000

[7] LUO Gusong. Based on the user experience of B2C e-commerce website comprehensive evaluation of the quality of service .2011-01

[8] Dong Jianming.Fu Limin,Rao Peilun,et al.HCI: user-centered Design and Assessment. 4nd ed. Beijing: Tsinghua University Press,2013( in Chinese)

[9] Fang Wentao. A Study on Factors Influencing Consumer Trust in the Proeess of Network Shopping. Shandong University,2011

[10] Lu J, Chen Q, Chen X. App interface study on how to improve user experience//Computer Science \& Education (ICCSE), 2012 7th International Conference on. IEEE, 2012: 726-729.

[11] Miller J. The user experience [Internet] . Internet Computing, IEEE, 2005, 9(5): 90-92.

[12] Li Y, Zhou P. Research on B2B e-commerce site information architecture based on user experience//E-Business and E-Government (ICEE), 2011 International Conference on. IEEE, 2011: 1-4.

[13] TMall[EB/OL].: http://mobile.tmall.com/index.shtml,2013:

[14] Jingdong Mall[EB/OL].:http://app.jd.com/,2013:

[15] Suning[EB/OL].:http://sale.suning.com/images/advertise/hg/20120419x sjkhd/index.html, 2013:

[16] TencentB2C[EB/OL].:http://act.m.buy.qq.com/pc/pcSpread.xhtml?gcfa $=20810021 \& \_1 p=1,2013$ :

[17] VANCL[EB/OL].:http://m.vancl.com/m/,2013:

[18] AmazonChina[EB/OL].:http://www.amazon.cn,2013:

[19] Coo8[EB/OL].: http://www.coo8.com/,2013:

[20] Dangdang[EB/OL]:http://static.dangdang.com/topic/744/200778. shtml, 2013:

[21] 51buy[EB/OL].: http://event.51buy.com/event/1092723.html,2013:

[22] Newegg[EB/OL].: http://app.newegg.com.cn/,2013: 